\title{
ARTICLE Sex, stress, and prefrontal cortex: influence of biological sex on stress-promoted cocaine seeking
}

Elizabeth M. Doncheck ${ }^{1,3}$, Gage T. Liddiard ${ }^{1}$, Chaz D. Konrath ${ }^{1}$, Xiaojie Liu (D) ${ }^{2}$, Laikang Yu², Luke A. Urbanik (D) ${ }^{1}$, Matthew R. Herbst ${ }^{1}$, Margot C. DeBaker (D) ${ }^{1}$, Nicholas Raddatz ${ }^{1}$, Erik C. Van Newenhizen (iD), Jacob Mathy ${ }^{1}$, Marieke R. Gilmartin (D) ${ }^{1}$, Qing-song Liu ${ }^{2}$, Cecilia J. Hillard ${ }^{2}$ and John R. Mantsch ${ }^{1}$

Clinical reports suggest that females diagnosed with substance use disorder experience enhanced relapse vulnerability compared with males, particularly during stress. We previously demonstrated that a stressor (footshock) can potentiate cocaine seeking in male rats via glucocorticoid-dependent cannabinoid type-1 receptor (CB1R)-mediated actions in the prelimbic prefrontal cortex (PrL-PFC). Here, we investigated the influence of biological sex on stress-potentiated cocaine seeking. Despite comparable selfadministration and extinction, females displayed a lower threshold for cocaine-primed reinstatement than males. Unlike males, footshock, tested across a range of intensities, failed to potentiate cocaine-primed reinstatement in females. However, restraint potentiated reinstatement in both sexes. While sex differences in stressor-induced plasma corticosterone (CORT) elevations and defensive behaviors were not observed, differences were evident in footshock-elicited ultrasonic vocalizations. CORT administration, at a dose which recapitulates stressor-induced plasma levels, reproduced stress-potentiated cocaine-primed reinstatement in both sexes. In females, CORT effects varied across the estrous cycle; CORT-potentiated reinstatement was only observed during diestrus and proestrus. As in males, CORT-potentiated cocaine seeking in females was localized to the PrL-PFC and both CORT- and restraint-potentiated cocaine seeking required PrL-PFC CB1R activation. In addition, ex vivo whole-cell electrophysiological recordings from female layer V PrL-PFC pyramidal neurons revealed CB1R-dependent CORT-induced suppression of inhibitory synaptic activity, as previously observed in males. These findings demonstrate that, while stress potentiates cocaine seeking via PrL-PFC CB1R in both sexes, sensitivity to cocaine priming injections is greater in females, CORTpotentiating effects vary with the estrous cycle, and whether reactivity to specific stressors may manifest as drug seeking depends on biological sex.

Neuropsychopharmacology (2020) 45:1974-1985; https://doi.org/10.1038/s41386-020-0674-3

\section{INTRODUCTION}

Clinical reports suggest that cocaine-dependent women may experience greater relapse vulnerability than men [1, 2]. Women reportedly experience greater difficulty abstaining [3] and relapse incidence [4], and resume use for longer periods of time following relapse [5]. This heightened relapse vulnerability is a crucial, yet currently untreated, women's health issue. However, the neurobiological basis for this sex difference is poorly characterized.

Stress is a problematic contributor to relapse, as it is unpredictable and unavoidable in everyday life. Females appear more vulnerable to stress-promoted relapse. Cocaine-dependent women display greater stressor reactivity [6] and female rats are more sensitive to yohimbine-promoted cocaine seeking [7]. Understanding the basis for sex differences that translate to heightened relapse susceptibility during stress has great relevance for treatment. Indeed, some medications that target the stress response appear to more effectively reduce cocaine craving in women [8].

Clinical reports point to a complex relationship between stress and drug seeking [9]. Rather than serving as a direct trigger for relapse, stress often interacts with other factors to promote drug use $[10,11]$. We have established a rodent model to study these potentiating effects of stress, wherein male rats undergo selfadministration under conditions following which electric footshock is insufficient to reinstate extinguished cocaine seeking on its own but rather potentiates responding to an otherwise subthreshold priming dose of cocaine [12].

We have identified a role for glucocorticoid-dependent endocannabinoid mobilization in footshock-potentiated cocaine seeking in male rats. Corticosterone (CORT) potentiates cocaine-primed reinstatement via a mechanism that requires cannabinoid type-1 receptor (CB1R) activation [13]. These effects can be localized to the prelimbic prefrontal cortex (PrL-PFC), which sends a glutamatergic projection to the nucleus accumbens that has been implicated in the reinstatement of cocaine seeking in rodent models [14-18]. Stress-potentiated cocaine seeking is associated with increased excitability of pyramidal neurons attributable to a CB1R-dependent attenuation of inhibitory transmission resulting from reduced GABA release from PrL-PFC interneurons $[13,19]$.

Women display greater PFC activity during stress-induced craving than men [20]. Moreover, sex differences in PrL-PFC

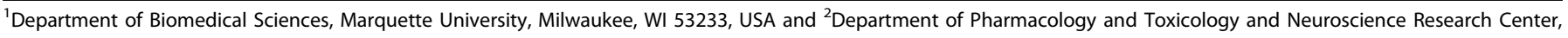
Medical College of Wisconsin, Milwaukee, WI 53226, USA

Correspondence: John R. Mantsch (john.mantsch@marquette.edu)

${ }^{3}$ Present address: Department of Neuroscience, Medical University of South Carolina, Charleston, SC 29425, USA

Received: 26 August 2019 Revised: 5 April 2020 Accepted: 7 April 2020

Published online: 17 April 2020 
activation during cocaine seeking [21] and in response to stressors [22] have been identified. Sex differences in PrL-PFC endocannabinoid signaling have also been reported [23]. For example, while males and females express CB1Rs on the same PrL-PFC GABAergic interneuron terminals $[19,24], C B 1 R$ affinity is reduced in the female PrL-PFC [25].

Here we investigate potential sex differences in stressor-related cocaine seeking and the underlying neurobiological mechanisms. Stressor-potentiated cocaine-primed reinstatement following intravenous self-administration and corresponding behavioral and hormonal responses were systematically examined in male and female rats, as was the contribution of CORT-dependent PrLPFC endocannabinoid signaling.

\section{MATERIALS AND METHODS}

Subjects

Female ( 90 days old $/ 250 \mathrm{~g}$ minimum at study onset) and male (90 days old $/ \leq 300 \mathrm{~g}$ at study onset) Sprague Dawley rats were single-housed under a reversed 12:12 h light-dark cycle (lights off at $0700 \mathrm{~h}$; see Supplementary Methods). All experiments were performed in accordance with the NIH Guide for the Care and Use of Laboratory Animals (8th ed.) and IACUC-approved.

\section{Chemicals/drugs}

Cocaine hydrochloride was obtained through the NIDA Drug Supply Program. CORT was obtained from Steraloids. 2-Hydroxypropyl- $\beta$-cyclodextrin- (HBC-) CORT and AM251 were purchased from Sigma-Aldrich. For electrophysiological recordings, TTX, CNQX, D-AP5, AM251, and CORT were obtained from Tocris Bioscience. All other chemical reagents were obtained from Sigma-Aldrich.

Intravenous catheterization and intracranial cannulation Rats were implanted with intravenous catheters for cocaine selfadministration and, in some cases, with PrL-PFC-targeted intracranial cannulae $(\mathrm{A} / \mathrm{P}+2.8 \mathrm{~mm}, \mathrm{M} / \mathrm{L}+1.0 \mathrm{~mm}, \mathrm{D} / \mathrm{V}-3.5 \mathrm{~mm})$ under isoflurane anesthesia as described $[13,26]$. See Supplementary Methods for details.

\section{Cocaine self-administration}

Rats were trained to self-administer cocaine $(0.2 \mathrm{mg} / 0.2 \mathrm{ml}$ infusion) by pressing a lever under a fixed-ratio 4 schedule of reinforcement during daily $2 \mathrm{~h}$ sessions as previously described $[13,26]$, with minor adaptations (see Supplementary Methods). Once trained, rats self-administered for 10-14 daily sessions prior to undergoing extinction training, during which the cocaine solution was replaced with saline. Once extinction criteria were met $(<15$ lever presses within 2 of 3 consecutive sessions), rats underwent reinstatement testing using a counter-balanced design.

\section{Footshock}

Rats were exposed to pseudo-randomly delivered $0.2 \mathrm{~s}$ triplicate footshocks through the floor grids of the experimental chambers over a 15 min period, with $40 \mathrm{~s}$ (average) inter-trial intervals. Males were tested for shock-potentiated cocaine seeking at $0.6 \mathrm{~mA}$, as previously described [13], while females were tested across a range of intensities $(0.15,0.30,0.60$, or $0.90 \mathrm{~mA})$. Levers were retracted and stimulus lights were off during the shock period, after which rats received an intraperitoneal (ip) cocaine or saline injection prior to initiation of the $2 \mathrm{~h}$ reinstatement session.

Restraint

Rats underwent 15 min of immobilization restraint using DecapiCone bags (BrainTree Scientific DC 200) outside of the operant conditioning chambers or remained in the home cage for $15 \mathrm{~min}$ prior to cocaine or saline administration and reinstatement testing.
Plasma CORT

Trunk blood was collected following rapid decapitation between 1030 and $1230 \mathrm{~h}$ after $15 \mathrm{~min}$ footshock, restraint, or context exposure, or $5,15,30$, or 45 min following systemic CORT ( $2 \mathrm{mg} / \mathrm{kg}$, ip) or vehicle administration. Plasma CORT levels were analyzed by ELISA (Enzo Life Sciences) per the manufacturer's protocol with the addition of a $5 \mathrm{~min} 98^{\circ} \mathrm{C}$ incubation in steroid dissociation reagent to fully dissociate CORT from binding globulins. Absent this optimization, CORT levels erroneously appeared $2-3 \times$ lower in females likely due to greater binding globulin levels [27].

Defensive behaviors

Defensive behaviors elicited by footshock were assessed during the 15 min sessions. Freezing behavior was defined as the cessation of all movement except that required for respiration, and freezing duration of at least $2 \mathrm{~s}$ following footshock offset was used to define latency [28]. Defensive darts were defined as rapid, forward movement across the chamber that resembled an active escapelike behavior [29]. All behaviors were scored using FreezeScan 2.0 (CleverSys). See Supplementary Methods for details.

Ultrasonic vocalizations (USVs)

Sonorous activity was recorded using condenser microphones (CM16, Avisoft Bioacoustics) suspended inside chambers housed within sound-attenuating cubicles (Coulbourn Instruments). Recorded.wav files were manually scored for total number and average durations of $20-22$ and $50-55 \mathrm{kHz}$ USVs using Raven Pro 1.4 software (Cornell Lab of Ornithology) similar to previous reports $[30,31]$. See Supplementary Methods for details.

Estrous phase tracking

Vaginal lavage samples were collected daily following behavioral testing. Estrous phases were identified using a Nikon Eclipse 55i microscope according to cell types visualized by Papanicolaou stain as previously described [26]. Predominant expression of large, round, nucleated epithelial cells defined proestrus; large, cornified anucleated epithelial cells defined estrus; leukocytes defined diestrus; and a combination of all three cell types defined metestrus.

Statistics

For behavioral and stressor assessments, statistical analyses were conducted using SPSS software and consisted of ANOVAs followed by Bonferroni-corrected $t$-tests. Electrophysiological data were analyzed using Minianalysis (Synaptosoft) by two-way ANOVA followed by Tukey's-corrected post-hoc and Kolmogorov-Smirnov t-tests. All results are expressed as mean \pm SEM. Statistical significance was defined as $P<0.05$.

Experiment 1: Sex comparison of cocaine-primed reinstatement Male $(n=19)$ and female $(n=16)$ rats underwent cocaine selfadministration and extinction and were tested for reinstatement in response to cocaine priming doses $(1.25,2.5$, or $5.0 \mathrm{mg} / \mathrm{kg}$, ip) or saline in counter-balanced sequence, administered immediately prior to the $2 \mathrm{~h}$ reinstatement session. Rats were re-extinguished to criterion between tests.

Experiment 2: Sex comparison of stressor-potentiated cocaine seeking and reactivity

Rats were tested for the ability of footshock (male $n=29$; female $n=6$ ) or restraint (male $n=10$; female $n=11$ ) to potentiate reinstatement when combined with subthreshold cocaine doses identified in Experiment $1(1.25 \mathrm{mg} / \mathrm{kg}$, ip in females and $2.5 \mathrm{mg} / \mathrm{kg}$, ip in males). Generally, rats were tested under the following conditions in counter-balanced sequences: no stressor/ saline, stressor/saline, no stressor/subthreshold cocaine, stressor/ subthreshold cocaine. However, males tested for the effects of footshock on reinstatement were only tested once in one of the 
previously listed conditions and were consequently analyzed using a between-subjects two-way (treatment condition $\times$ day) ANOVA. Plasma CORT levels, defensive behaviors, and USVs were assessed (male $n=16$; female $n=16$ ).

Experiment 3: Sex comparison of CORT-potentiated reinstatement Sex differences in stress-level CORT-potentiated reinstatement (male $n=12$; female $n=19$ ) were tested under the following conditions: CORT ( $2 \mathrm{mg} / \mathrm{kg}$, ip in $10 \%$ ethanol in saline; $40 \mathrm{~min}$ pretreatment)/ saline, CORT/subthreshold cocaine, vehicle/saline, vehicle/subthreshold cocaine. CORT effects on reinstatement responding to the identified subthreshold cocaine priming dose for the opposite sex were also assessed (male $n=12$; female $n=8$ ). Females were tested for CORT-potentiated reinstatement across the estrous cycle $(n=24$; testing between 0730 and $1200 \mathrm{~h}$ ) determined using daily vaginal lavage samples. Plasma CORT levels were measured in both sexes following CORT administration (male $n=32$; female $n=32$ ). The influence of the estrous cycle on cocaine self-administration and extinction was not assessed.

\section{Experiment 4: Sex comparison of PrL-PFC CB1R-dependent} restraint-potentiated reinstatement

Males $(n=7)$ and females $(n=7)$ were implanted with bilateral intracranial cannulae targeting the PrL-PFC and tested for reinstatement testing under the following conditions: intra-PrL vehicle/ restraint (15 $\mathrm{min}) /$ saline; intra-PrL vehicle/no restraint/saline; intra-PrL vehicle/no restraint/cocaine (1.25 or $2.5 \mathrm{mg} / \mathrm{kg}$, ip), intra-PrL vehicle/ restraint/cocaine, intra-PrL AM251 (300 ng/0.3 $\mu \mathrm{L} / \mathrm{side}, 15 \mathrm{~min}$ pretreatment)/restraint/cocaine. Cannula placements were confirmed. No misses were found. AM251 effects on cocaine seeking under no restraint/saline, no restraint/cocaine, and restraint/saline conditions were not tested.

Experiment 5: Assessment of PrL-PFC CORT- and CB1R-dependent reinstatement and electrophysiological activity in females Female rats $(n=13)$ were implanted with bilateral cannulae targeting the PrL-PFC and tested for reinstatement under the following conditions: intra-PrL HBC-CORT ( $50 \mathrm{ng} / 0.3 \mu \mathrm{L} / \mathrm{side}, 15 \mathrm{~min}$ pretreatment)/saline, intra-PrL $\mathrm{HBC} /$ saline, intra-PrL HBC-CORT/ cocaine (1.25 mg/kg, ip), intra-PrL HBC/cocaine. Cannula placements were confirmed, and misses were excluded $(n=1)$.

Female rats $(n=7)$ were tested for CB1R regulation of reinstatement under the following conditions: PrL vehicle/CORT ( $2 \mathrm{mg} / \mathrm{kg}$, ip; $1 \mathrm{~h}$ pretreatment)/saline; $\operatorname{PrL}$ vehicle/vehicle/saline; $\operatorname{PrL}$ vehicle/ vehicle/cocaine $(1.25 \mathrm{mg} / \mathrm{kg}$, ip), $\mathrm{PrL}$ vehicle/CORT/cocaine, $\mathrm{PrL}$ AM251 (300 ng/0.3 $\mu \mathrm{L} / \mathrm{side}, 15 \mathrm{~min}$ pretreatment)/CORT/cocaine. Anatomical misses were excluded $(n=1)$. AM251 effects on cocaine seeking under vehicle/saline, vehicle/cocaine, and CORT/saline conditions were not tested.

Patch-clamp electrophysiological recordings were taken from female coronal slices containing the PrL-PFC following bath application of CORT $(1 \mu \mathrm{M})$ or vehicle with AM251 $(1 \mu \mathrm{M})$ or vehicle. Recording details are included in Supplementary Methods. For analysis, mIPSC amplitude was normalized to baseline, and the depression (\%) of mIPSCs by CORT was calculated as follows: $100 \times$ [mean amplitude of IPSCs during final $5 \mathrm{~min}$ of treatment/mean amplitude of baseline mIPSCs]. Analysis of mIPSCs was performed with cumulative probability plots [32].

\section{RESULTS}

Experiment 1: Cocaine-primed reinstatement dose-response testing

No sex differences in acquisition, maintenance, or extinction of cocaine self-administration were observed (Table S1). Males and females exhibited equivalent latencies to acquire (Fig. 1a), responding during maintenance (Fig. 1b), and extinction behavior (Fig. 1c). Despite similarities in self-administration and extinction, females reinstated in response to lower cocaine priming doses (Fig. 1d, e). A three-way repeated-measures ANOVA revealed a significant sex (male vs. female) $\times$ day (extinction vs. reinstatement) $\times$ dose $(0$, $1.25,2.5$, or $5 \mathrm{mg} / \mathrm{kg}$ cocaine $)$ interaction $\left(F_{(3,170)}=8.736, p<\right.$ $0.0001)$. In males, a two-way day $\times$ dose ANOVA revealed main effects of day $\left(F_{(1,98)}=34.59, p<0.0001\right)$ and dose $\left(F_{(3,98)}=5.345\right.$, $p<0.01)$, and a significant interaction $\left(F_{(3,98)}=5.747, p<0.01\right)$. Posthoc testing showed that significant reinstatement was only observed at $5.0 \mathrm{mg} / \mathrm{kg}$ cocaine ( $p<0.001$ vs. extinction). In females, a two-way day $\times$ dose ANOVA also revealed main effects of day $\left(F_{(1,72)}=39.47, p<0.0001\right)$ and dose $\left(F_{(3,72)}=17.45, p<0.0001\right)$, and a significant interaction $\left(F_{(3,72)}=15.19, p<0.0001\right)$. Significant reinstatement (vs. extinction) was observed in response to $2.5 \mathrm{mg} / \mathrm{kg}(p<0.05)$ and $5.0 \mathrm{mg} / \mathrm{kg}(p<0.001)$ cocaine. Based on these results, $2.5 \mathrm{mg} / \mathrm{kg}$ cocaine was selected as the subthreshold priming dose to be used for testing for potentiated cocaine seeking in males and $1.25 \mathrm{mg} / \mathrm{kg}$ as the subthreshold dose in females. Posthoc analysis revealed that reinstatement following administration of the $5 \mathrm{mg} / \mathrm{kg}$ cocaine dose, but not the other doses tested was significantly increased in females relative to males $(p<0.05)$.

Experiment 2: Sex comparison of stressor-potentiated cocaine seeking and stressor reactivity

Footshock stress. To determine if stressors can similarly potentiate cocaine-induced reinstatement in males and females, rats were initially tested for the effects of footshock (Fig. 2a). A three-way repeated-measures ANOVA revealed a significant sex (male vs. female) $\times$ day (extinction vs. reinstatement) $\times$ treatment (no shock/ saline, no shock/cocaine, shock/cocaine) interaction $\left(\mathrm{F}_{(2,66)}=6.499\right.$, $p<0.01)$. Footshock-potentiated cocaine-induced reinstatement in males (Fig. 2b). A two-way ANOVA revealed a significant reinstatement $\times$ shock/cocaine condition interaction $\left(F_{(3,38)}=6.823, p<\right.$ 0.001 ). Post-hoc analysis showed that neither $2.5 \mathrm{mg} / \mathrm{kg}$ cocaine nor footshock alone reinstated cocaine seeking. However, when combined, the two stimuli produced significant reinstatement ( $p<0.001$ vs. extinction and the no shock/saline, no shock/cocaine, and shock/saline conditions). By contrast, females did not exhibit footshock-potentiated reinstatement at any intensity tested $(0.15$, $0.3,0.6,0.9 \mathrm{~mA})$ in combination with the $1.25 \mathrm{mg} / \mathrm{kg}$ cocaine priming dose (Fig. 2c).

Restraint stress. Restraint potentiated cocaine-primed reinstatement in both males (Fig. 2d) and females (Fig. 2e). A three-way between-subjects ANOVA did not reveal a significant interaction between sex (male vs. female), day (reinstatement vs. extinction), and treatment (no restraint/saline, restraint/saline, no restraint/ cocaine, restraint/cocaine; $\left.\left.\left(F_{(3,136}=0.310\right), p=0.818\right)\right)$. Two-way ANOVAs revealed significant day $\times$ treatment condition interactions in both males and females. Post-hoc analysis revealed that while neither restraint nor subthreshold cocaine $(2.5 \mathrm{mg} / \mathrm{kg}$ in males; $1.25 \mathrm{mg} / \mathrm{kg}$ in females) alone reinstated cocaine seeking, restraint in combination with cocaine produced significant reinstatement in both sexes (males: $F_{(3,28)}=3.159, p<0.05$, posthoc $p<0.01$ vs. extinction, no restraint/saline, and restraint/saline conditions; females $F_{(3,40)}=3.021, p<0.05$, post-hoc $p<0.05$ vs. extinction, no restraint/saline, and restraint/saline conditions).

Plasma CORT. To determine if differences in stressor-potentiated reinstatement were associated with differences in the CORT response, basal and stressor-induced plasma CORT immediately following $15 \mathrm{~min}$ of shock or restraint was compared between sexes (Fig. 2f). A sex $x$ stress/condition ANOVA found that, while there were significant main effects of $\operatorname{sex}\left(F_{(1,18)}=26.39, p<0.01\right)$ and stressor $\left(F_{(2,18)}=37.38, p<0.0001\right)$ on plasma CORT, there was no sex $\times$ stressor interaction. Overall females had higher CORT levels. A planned comparison revealed that this was likely attributable to increased basal CORT levels (unpaired $t$ test, $t_{(6)}$ $=3.332, p<0.05$ ). Overall, shock and restraint elevated CORT 

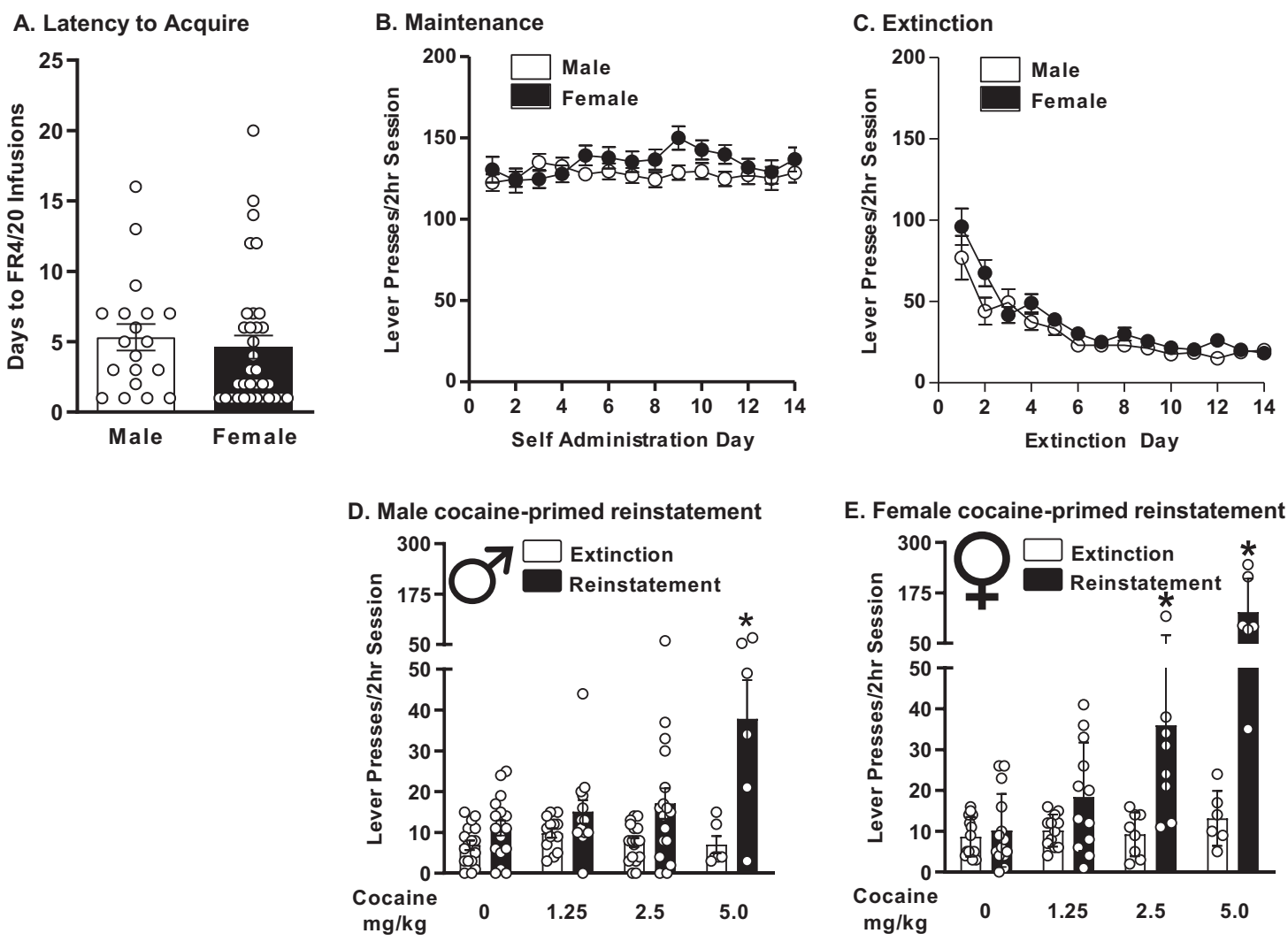

Fig. 1 Sex comparison of acquisition, maintenance, and extinction of cocaine self-administration, and cocaine-primed reinstatement (male $n=49$, female $n=34$ ). a Latency to acquire cocaine self-administration under a fixed-ratio 4 schedule of reinforcement with a minimum requirement of $\geq 200.2 \mathrm{mg} / 0.2 \mathrm{~mL}$ cocaine infusions. b Maintenance of cocaine self-administration. c Extinction of cocaine selfadministration. d Male cocaine-primed reinstatement dose-response curve $(0,1.25,2.5$, and $5.0 \mathrm{mg} / \mathrm{kg}$, ip; $* * * p<0.001 \mathrm{vs}$. prior extinction). e Female cocaine-primed reinstatement dose-response curve $\left(0,1.25,2.5\right.$, and $5.0 \mathrm{mg} / \mathrm{kg}$, ip) $\left({ }^{*} p<0.05\right.$ or ${ }^{* * *} p<0.001$ vs. prior extinction). Data are represented as mean \pm SEM.

relative to baseline ( $p<0.001$ for each stressor) and the magnitude (i.e., increase from baseline) of the stressor-induced CORT response did not differ across stressors or between sexes. A sex $\times$ stressor (shock vs. restraint) ANOVA failed to reveal significant effects of sex, stressor type or a sex $\times$ stressor interaction (Fig. 2g).

Defensive behaviors. To determine if the lack of footshockpotentiated cocaine seeking in females was attributable to a general increase or decrease in shock reactivity relative to males, we also examined defensive behaviors, including freezing and defensive darting. No sex differences in average percent freezing behavior over the 15 min session were observed (Fig. 2h). A twoway repeated-measures ANOVA revealed a main effect of footshock $\left(F_{(1,14)}=262.1, p<0.0001\right)$, but no main effect of sex or interaction. We further assessed freezing in response to the first and last three shocks in the 15 min session (Fig. S1A) and the postshock freezing latency across the session (Fig. S1B) and found no sex differences. We also assessed darting behavior, previously characterized as activity bursts primarily observed in females following shocks [33] and found a trend toward an increase in females (Fig. S1C; $p=0.07$ ).

Ultrasonic vocalizations (USVs). To examine potential sex differences in emotional/affective processing, USVs were recorded over a $15 \mathrm{~min}$ baseline period and during exposure to footshock or restraint. Total numbers of $20-22 \mathrm{kHz}$ USVs and $50-55 \mathrm{kHz}$ USVs during each 15 min period are shown in Fig. $2 \mathrm{i}, \mathrm{j}$, respectively. In contrast to defensive behaviors, sex differences in stressor-evoked USVs were observed, but only during footshock. For each frequency range, a two-way sex $\times$ stressor condition (baseline, restraint, footshock)
ANOVA examining effects on the total number of calls revealed significant main effects of stressor condition $\left(F_{(2,16)}=14.92, p<0.001\right)$ and sex $\left(F_{(1,8)}=12.17, p<0.01\right)$ for $20-22 \mathrm{kHz}$ calls, and sex $\times$ stressor condition interactions for $20-22 \mathrm{kHz}\left(F_{(2,16)}=11.39, p<0.001\right)$ and for $50-55 \mathrm{kHz}$ calls $\left(F_{(2,12)}=3.84, p<0.05\right)$. Overall, the number of $20-22 \mathrm{kHz}$ USVs increased while the number of $50-55 \mathrm{kHz}$ USVs generally decreased during stressor exposure. While there were no sex differences in USVs at baseline, males emitted significantly more $20-22 \mathrm{kHz}$ USVs than females $(p<0.001)$. While there were no differences from respective baselines for either sex, males also emitted significantly fewer $50-55 \mathrm{kHz}$ USVs than females $(p<0.05)$ during the footshock session. When deconstructed by stressor, a main effect of restraint (baseline vs. restraint) was observed in both $20-22 \mathrm{kHz}\left(\mathrm{F}_{(1,8)}=9.93, p<0.05\right)$ and $50-55 \mathrm{kHz}\left(F_{(1,6)}=11.39, p<\right.$ 0.05 ) total calls, regardless of sex, with an increase in $20-22 \mathrm{kHz}$ calls and a reduction in $50-55 \mathrm{kHz}$ calls. For $20-22 \mathrm{kHz}$ calls during baseline vs. footshock stress, there was a main effect of shock condition $\left(F_{(1,8)}=17.77, p<0.01\right)$, sex $\left(F_{(1,8)}=12.15, p<0.01\right)$, and a significant stress $\times$ sex interaction $\left(F_{(1,8)}=11.72, p<0.01\right)$. Sex differences in the distribution of USVs during stressor sessions were not observed, nor were differences in the durations of USVs when analyzed according to frequency subtype (i.e., $>250 \mathrm{~ms}$, versus $<100 \mathrm{~ms} 22 \mathrm{kHz}$ calls; Fig. S2B-F, H-I). However, overall, females emitted more short-call $22 \mathrm{kHz}$ USVs, whereas males emitted more long-call $22 \mathrm{kHz}$ USVs.

Experiment 3: Sex comparison in CORT-potentiated reinstatement of cocaine seeking CORT-potentiated reinstatement. CORT $(2 \mathrm{mg} / \mathrm{kg}$, ip; $40 \mathrm{~min}$ pretreatment; Fig. 3a) potentiated cocaine-induced reinstatement in both sexes (males Fig. 3b; females Fig. 3c). A three-way 
A. Reinstatement timeline

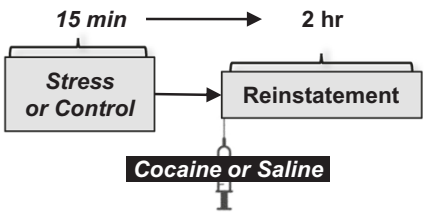

B. Male footshock-potentiated reinstatement

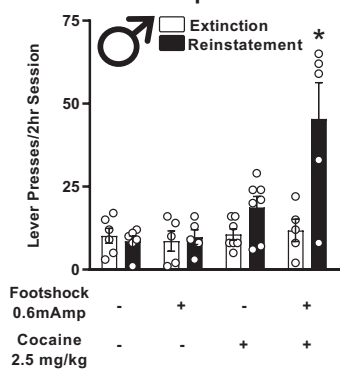

D. Male restraint-potentiated reinstatement

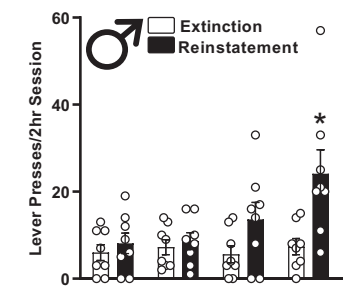

Restraint

Cocaine $2.5 \mathrm{mg} / \mathrm{kg}$

H. Average Freezing Per Footshock Session

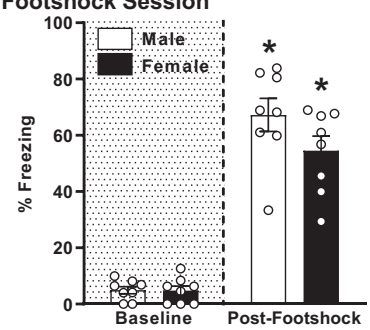

E. Female restraint-potentiated reinstatement
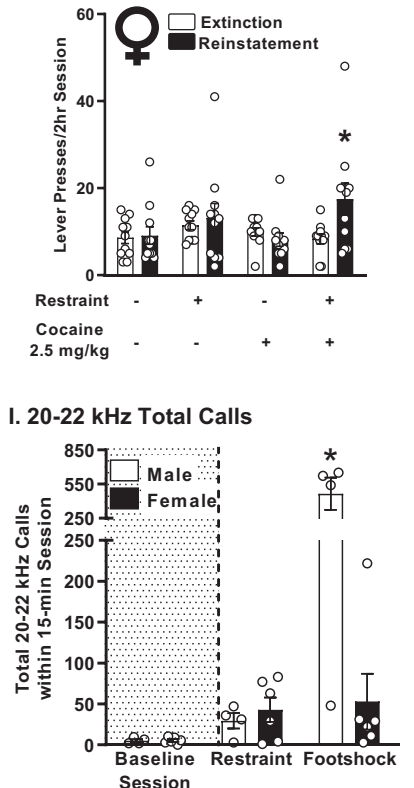

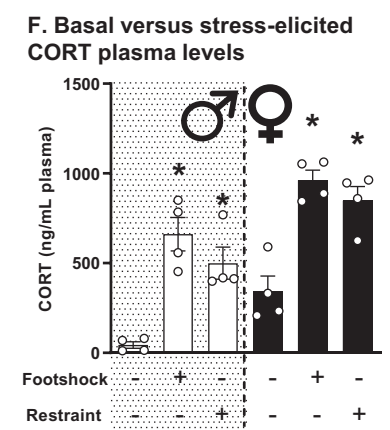

G. Basal corrected stresselicited CORT plasma levels

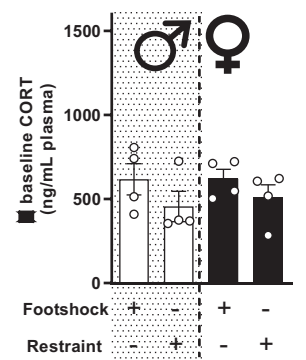

C. Female footshock-potentiated reinstatement

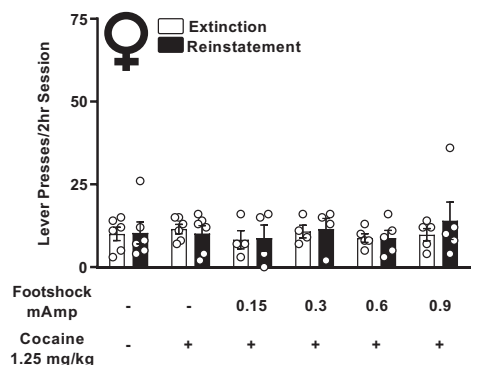

J. 50-55 kHz Total Calls

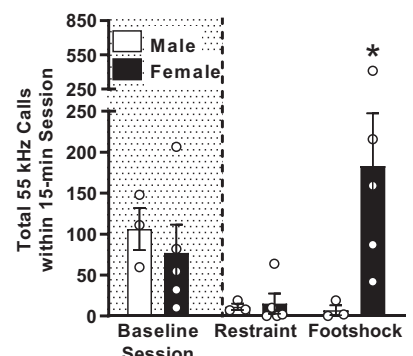

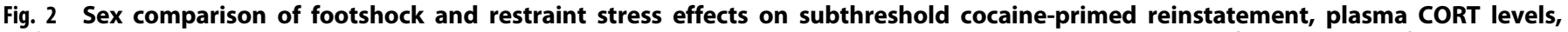

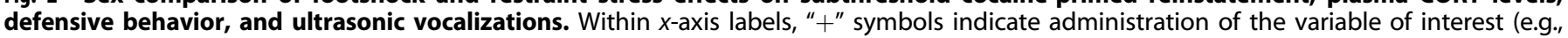

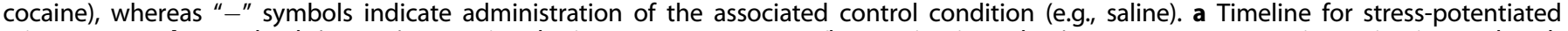

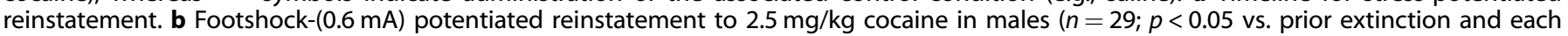

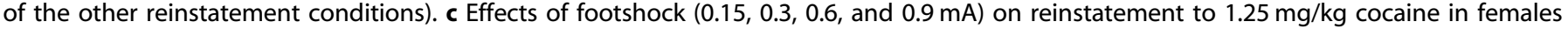

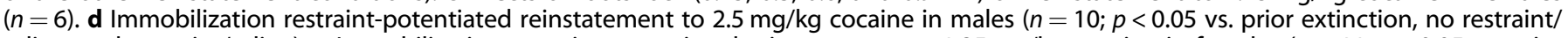

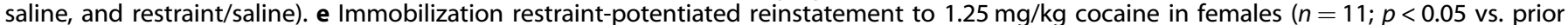

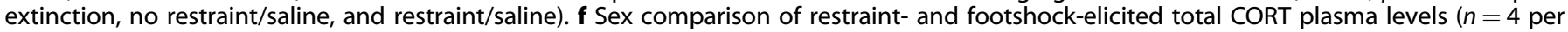

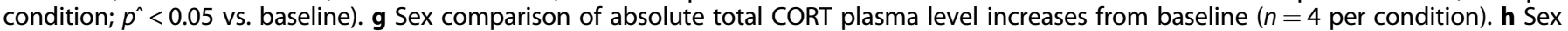

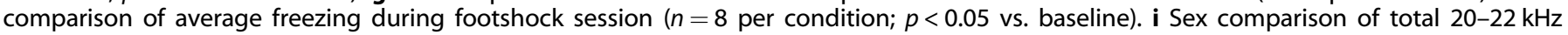

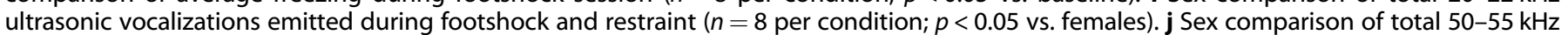

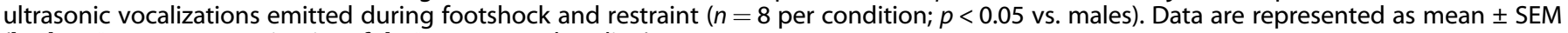
(b, d, e: ${ }^{*} p<0.05$ vs. extinction; $\mathbf{f}, \mathbf{h}:{ }^{*} p<0.05$ vs. baseline).

between-subjects ANOVA revealed no significant interaction between sex (male vs. female), day (extinction vs. reinstatement), and treatment (vehicle/saline, CORT/saline, vehicle/cocaine, CORT/cocaine; $\left.F_{(2,180)}=1.013, p=0.388\right)$. In both sexes, twoway reinstatement $\times$ treatment condition ANOVA revealed significant main effects of reinstatement $\left(F_{(1,33)}=19.03, p<\right.$ 0.0001 in males; $F_{(1,52)}=9.38, p<0.01$ in females) and treatment $\left(F_{(3,33)}=3.694, \quad p<0.05\right.$ in males; $F_{(3,52)}=4.67, p<0.01$ in females), and significant interactions $\left(F_{(3,33)}=4.484, p<0.01\right.$ in males; $F_{(3,52)}=5.82, p<0.01$ in females). In both cases, post-hoc testing showed that neither CORT nor cocaine $(2.5 \mathrm{mg} / \mathrm{kg}$ in males and $1.25 \mathrm{mg} / \mathrm{kg}$ in females) alone produced reinstatement, but that significant reinstatement was observed in both sexes when CORT was administered prior to the subthreshold cocaine dose ( $p<0.05$ vs. extinction, vehicle/saline, vehicle/cocaine, and CORT/saline conditions). To further examine CORT-potentiated cocaine seeking, we also tested for effects of CORT on reinstatement in combination with $1.25 \mathrm{mg} / \mathrm{kg}$ cocaine in males and $2.5 \mathrm{mg} / \mathrm{kg}$ cocaine in females (Fig. S3A, B). Dose-response testing indicated that CORT produces a leftward shift in the dose-response curve for cocaine-induced reinstatement in both sexes, consistent with increased cocaine sensitivity. A three-way between-subjects ANOVA revealed no significant interactions between sex (male vs. female), day (extinction vs. reinstatement), and treatment (vehicle/saline, vehicle/cocaine-1.25, vehicle/ cocaine-2.5, CORT/saline, CORT/cocaine-1.25, CORT/cocaine-2.5; $\left.F_{(5,238)}=0.987, p=0.426\right)$.

Estrous phase-dependent effects of CORT. As the level of CORTpotentiation tended to be lower in females than in males, estrous cycle interactions with CORT-potentiated reinstatement were assessed. Overall, a three-way between-subjects ANOVA did not reveal a significant interaction between estrous phase (proestrus, estrus, metestrus, or diestrus), day (extinction vs. reinstatement), 
A. Reinstatement timeline

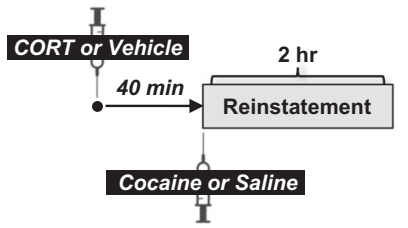

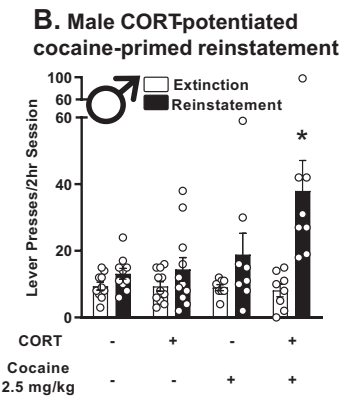

E. CORT + saline reinstatement across the estrous cycle

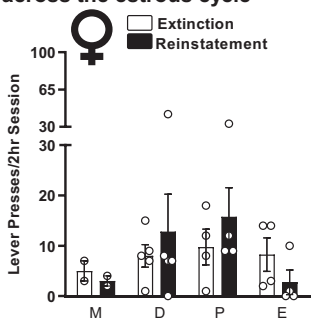

F. Vehicle + cocaine reinstatement across the estrous cycle

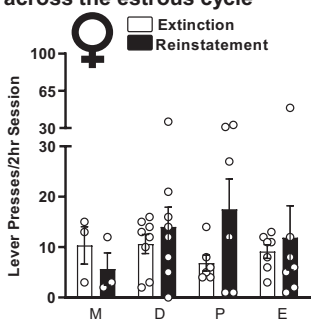

I. Male exogenous CORT-induced CORT plasma levels
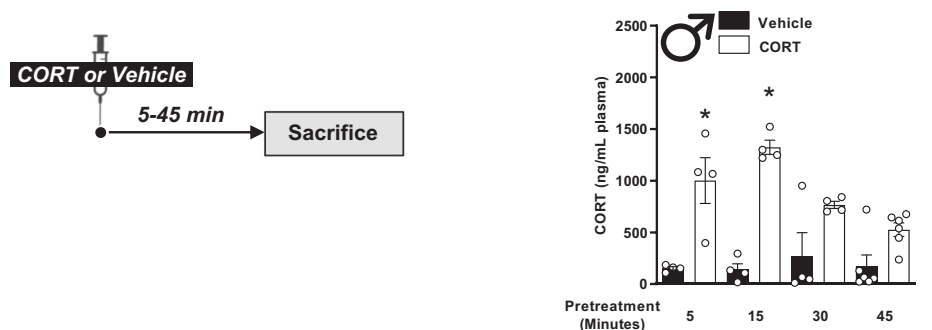

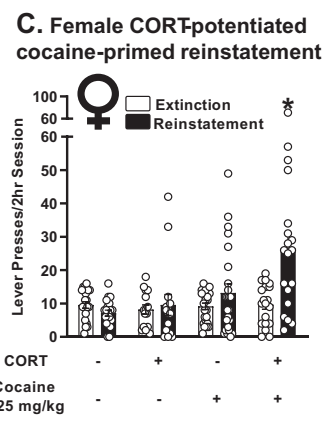

G. CORT+ cocaine reinstatement across the estrous cycle

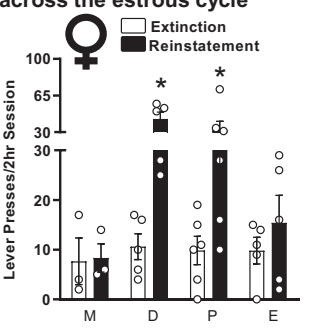

J. Female exogenous CORT-induced

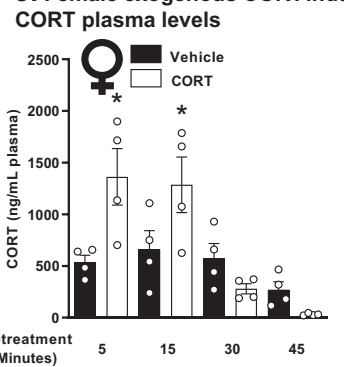

Fig. 3 Sex comparison of exogenous CORT effects on subthreshold cocaine-primed reinstatement and CORT plasma levels. Within $x$-axis labels, "+" symbols indicate administration of the variable of interest (e.g., cocaine), whereas "_" symbols indicate administration of the associated control condition (e.g., saline). a CORT-potentiated reinstatement timeline. b CORT- (2 mg/kg, ip) potentiated reinstatement in response to $2.5 \mathrm{mg} / \mathrm{kg}$ cocaine in males ( $n=12 ; p^{\wedge}<0.05 \mathrm{vs}$. extinction). c CORT- $(2 \mathrm{mg} / \mathrm{kg}$, ip) potentiated reinstatement in response to $1.25 \mathrm{mg} / \mathrm{kg}$ cocaine in females ( $n=19 ; p^{\wedge}<0.05 \mathrm{vs}$. extinction). $\mathbf{d}$ Reinstatement to vehicle and saline across the estrous cycle in females ( $n=$ 20). e Reinstatement to $2 \mathrm{mg} / \mathrm{kg}$ CORT and saline across the estrous cycle in females $(n=15)$. f Reinstatement to vehicle and $1.25 \mathrm{mg} / \mathrm{kg}$ cocaine across the estrous cycle in females $(n=21)$. g Reinstatement to $2 \mathrm{mg} / \mathrm{kg}$ CORT and $1.25 \mathrm{mg} / \mathrm{kg}$ cocaine across the estrous cycle in females ( $n=19 ; p^{\wedge}<0.05$ vs. diestrus vs. metestrus and estrus, proestrus vs. metestrus). h Timeline for plasma collection for CORT measurement. i Exogenous CORT-induced total CORT plasma levels 5, 15, 30, and 45 min following administration in males $(n=4-6$ per condition; $p^{\wedge}<0.05$ vs. vehicle). $\mathbf{j}$ Exogenous CORT-induced total CORT plasma levels 5, 15, 30, and 45 min following administration in females $\left(n=4\right.$ per condition; $p^{\wedge}<0.05$ vs. vehicle). Data are represented as mean \pm SEM.

and treatment (vehicle/saline, CORT/saline, vehicle/cocaine, and CORT/cocaine; $\left.F_{(6,130)}=0.221, p=0.969\right)$. Furthermore, when analyzing estrous cycle variation in reinstatement (relative to extinction) in response to vehicle/saline (Fig. 3d), CORT/saline (Fig. 3e), or vehicle/1.25 mg/kg cocaine (Fig. 3f), no differences were observed. However, significant reinstatement was observed in response to CORT $+1.25 \mathrm{mg} / \mathrm{kg}$ cocaine, but only during diestrus and proestrus (Fig. $3 \mathrm{~g}$ ). A two-way independent-measures ANOVA revealed a main effect of reinstatement $\left(F_{(1,30)}=13.43, p<\right.$ $0.01)$, treatment condition $\left(F_{(3,30)}=3.839, p<0.05\right)$, and a significant interaction $\left(F_{(1,30)}=3.028, p<0.05\right)$. Post-hoc testing revealed increased reinstatement in proestrus versus metestrus $(p<0.05)$ and during diestrus versus both metestrus and estrus ( $p s<0.01$ ).

Plasma CORT. To determine whether systemic CORT administration elicits similar blood levels in both sexes, a blood plasma level time-course sex comparison was made following administration of $2 \mathrm{mg} / \mathrm{kg}$ CORT (Fig. 3h). While a three-way ANOVA revealed no overall sex $\times$ time $(5,15,30,45$ min post injection $) \times$ treatment (vehicle vs. CORT) interaction $\left(F_{(3,52)}=1.296, \quad p=0.286\right)$, differences were observed. Basal (vehicle) CORT levels were higher in females at every timepoint $\left(F_{(1,26)}=12.90, p<0.01\right)$ and plasma levels similarly peaked $15 \mathrm{~min}$ after CORT administration in both sexes (Fig. 3i, j; $F_{(3.26)}=3.536, p<0.05$ ). No sex differences were observed in CORT level elevations observed at 5 $\left(F_{(1,12)}=0.004, p=0.951\right)$, or $15 \mathrm{~min}\left(F_{(1,12)}=2.747, p=0.123\right)$, but differences were observed at $30\left(F_{(1,12)}=8.335, p<0.05\right)$ and 45 $\min \left(F_{(1,17)}=12.927, p<0.01\right)$. Males exhibited persistent CORT elevations relative to vehicle (Fig. 3i). A two-way repeatedmeasures treatment (vehicle versus CORT) $\times$ time $(5,15,30$, or $45 \mathrm{~min})$ ANOVA revealed main effects of time $\left(F_{(3,28)}=3.760, p<\right.$ $0.05)$, treatment $\left(F_{(1,28)}=69.83, p<0.0001\right)$ and a significant interaction $\left(\mathrm{F}_{(3,28)}=4.852, p<0.01\right)$, with CORT levels increased after $5 \mathrm{~min}$, peak levels at $15 \mathrm{~min}$, and reductions at 30 and $45 \mathrm{~min}$ relative to the peak $(p<0.01)$ close to levels observed following vehicle. By contrast, following the $15 \mathrm{~min}$ peak, CORT levels in females rapidly declined to the point where they were below vehicle levels (Fig. 3j). A two-way repeated-measures treatment $x$ time ANOVA revealed a main effect of time $\left(F_{(3,24)}=12.21, p<\right.$ $0.0001)$ and a significant treatment $\times$ time interaction $\left(F_{(3,24)}=\right.$ 
$6.295, p<0.01$ ), with significantly lower CORT levels by $30 \mathrm{~min}$ and $45 \mathrm{~min}$ compared with $5 \mathrm{~min}$ and $15 \mathrm{~min}$ ( $p<0.001$ for each comparison), suggesting faster CORT clearance in females.

Experiment 4: Role of PrL-PFC CB1R activation in restraintpotentiated reinstatement. To test whether the effects of restraint on potentiated reinstatement require PrL-PFC CB1R activation in both sexes, as demonstrated with footshock in males [13], males and females underwent restraint-potentiation testing following intra-PrL CB1R antagonism (Fig. 4a; AM251, $300 \mathrm{ng} / 0.3 \mu \mathrm{L} / \mathrm{side}, 15 \mathrm{~min}$ pretreatment). Both males and females exhibited CB1R-dependent restraint-potentiated reinstatement (Fig. 4b, c). A three-way between-subjects ANOVA did not reveal a significant interaction between sex (male vs. female), day (reinstatement vs. extinction), and treatment (intra-PrL vehicle/no restraint/saline, intra-PrL vehicle/ restraint/saline, intra-PrL vehicle/no restraint/cocaine, intra-PrL vehicle/restraint/cocaine, $\operatorname{PrL} \mathrm{AM} 251 /$ restraint/cocaine; $\left(F_{(4,172)}=\right.$ $0.507, p=0.731)$ ). In both sexes, two-way independent-measures ANOVAs revealed significant reinstatement $\times$ treatment condition interactions $\left(F_{(4,74)}=2.849, p<0.05\right.$ for males; $F_{(4,46)}=1.496, p<0.05$ for females). Post-hoc comparisons revealed that while reinstatement was not observed following restraint or subthreshold cocaine alone $(2.5 \mathrm{mg} / \mathrm{kg}$ in males or $1.25 \mathrm{mg} / \mathrm{kg}$ in females), the cocaine/ restraint combination produced reinstatement following intra-PrL vehicle ( $p<0.01$ in males vs. extinction, restraint/saline, no restraint/ saline, and no restraint/cocaine and $p<0.05$ in females vs. extinction), no restraint/saline, and restraint/saline, but not intraPrL AM251. Moreover, intra-PrL AM251 significantly reduced cocaine seeking relative to vehicle-pretreatment in both males $(p<0.001)$ and females $(p<0.05)$. Accuracy of cannula placements was confirmed (males, Fig. S1A, C; females, Fig. S4B, D).

Experiment 5: CORT and CB1R-dependent effects in the PrL-PFC in female rats. As reported in males [13], CORT-potentiated cocaine seeking was localized to the PrL-PFC in females. Intra-PrL delivery of $\mathrm{HBC}$-CORT ( $50 \mathrm{ng} / 0.3 \mu \mathrm{L} / \mathrm{side}, 15 \mathrm{~min}$ pretreatment) did not increase cocaine seeking on its own, but potentiated cocaine seeking when combined with $1.25 \mathrm{mg} / \mathrm{kg}$ cocaine (Fig. 5a, b). A two-way repeated-measures reinstatement $\times$ treatment condition ANOVA revealed a main effect of reinstatement $\left(F_{(1,54)}=4.660\right.$, $p<0.05)$, and a significant interaction $\left(F_{(3,54)}=3.240, p<0.05\right)$. Post-hoc comparison showed that, in contrast to intra-PrL CORT alone or sham treatment combined with cocaine, the intra-PrL CORT/cocaine combination resulted in significant reinstatement ( $p<0.05$ vs. extinction, sham/saline, and $\operatorname{PrL}$ CORT/saline). Histology and cannula placements are depicted in Figs. S5a, c.

PrL-PFC CB1R involvement in CORT-potentiated reinstatement. As demonstrated in males [13], intra-PrL CB1R antagonism (AM251, $300 \mathrm{ng} / 0.3 \mu \mathrm{L} / \mathrm{side}, 15 \mathrm{~min}$ pretreatment) prevented CORTpotentiated reinstatement in females (Fig. 5c, d). A two-way independent-measures reinstatement $\times$ treatment condition

A. Reinstatement timeline

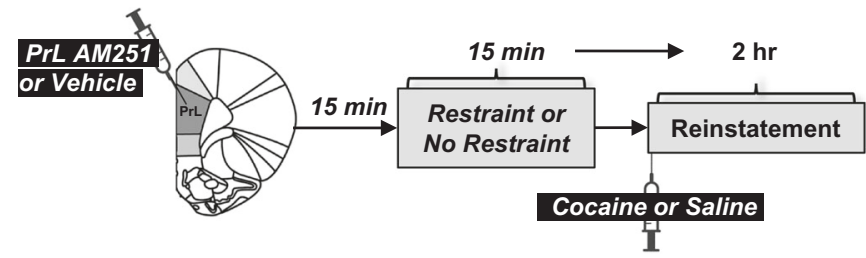

B. Male PrL-PFC CB1R antagonism of restraint-potentiated reinstatement

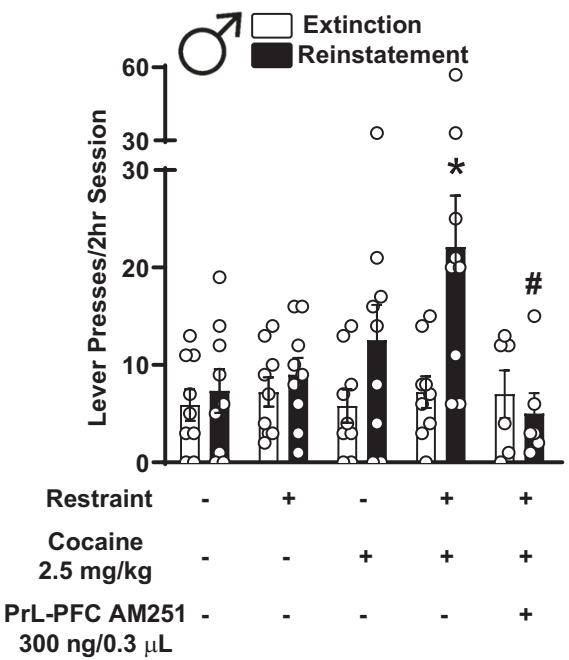

C. Female PrL-PFC CB1R antagonism of restraint-potentiated reinstatement

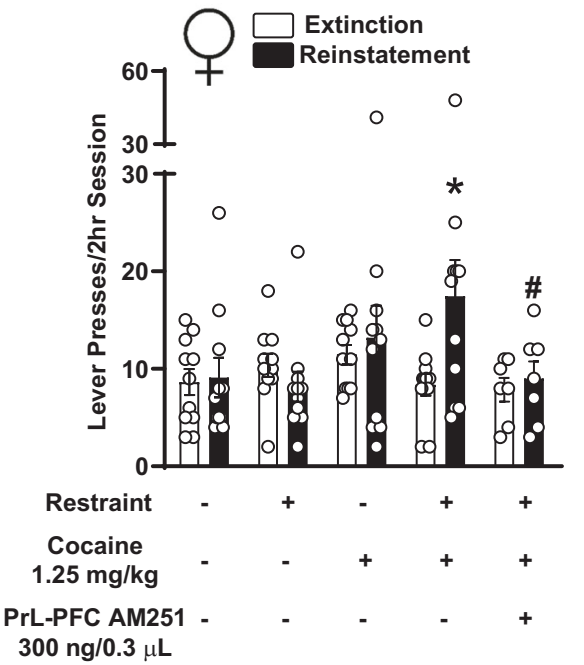

Fig. 4 Sex comparison of necessity for PrL-PFC CB1R activation in restraint-potentiated reinstatement. Within $x$-axis labels, "+" symbols indicate administration of the variable of interest (e.g., cocaine), whereas "-" symbols indicate administration of the associated control condition (e.g., saline). a Reinstatement timeline for examination of effects of PrL-PFC AM251 restraint-potentiated reinstatement. $\mathbf{b}$ Intra-PrL $300 \mathrm{ng} / 0.3 \mu \mathrm{L} \mathrm{AM} 251$ effects on restraint-potentiated reinstatement to $2.5 \mathrm{mg} / \mathrm{kg}$ cocaine in males $\left(n=7 ;{ }^{*} p<0.05 \mathrm{vs}\right.$. extinction). Restraintpotentiated reinstatement was observed following intra-PrL vehicle injections ( ${ }^{*} p<0.05$ vs. extinction and each of the other reinstatement conditions) and was significantly attenuated by intra-PrL AM251 ( ${ }^{*} p<0.05$ vs. veh/restraint/cocaine). c Intra-PrL $300 \mathrm{ng} / 0.3 \mu \mathrm{L}$ AM251 also prevented restraint-potentiated reinstatement at the $1.25 \mathrm{mg} / \mathrm{kg}$ cocaine dose in females $\left(n=7 ;{ }^{*} p<0.05\right.$ vs. extinction). Restraint-potentiated reinstatement was observed following intra-PrL vehicle injections $\left({ }^{*} p<0.05 \mathrm{vs}\right.$. extinction, no restraint/saline, and restraint/saline) and was significantly attenuated by intra-PrL AM251 ( $\# p<0.05$ vs. veh/restraint/cocaine). Data are represented as mean \pm SEM. 
Female PrL-PFC CORT is sufficient and CB1R activation is necessary for both potentiated reinstatement and suppression of pyramidal neuron inhibitory activity

A. Reinstatement timeline

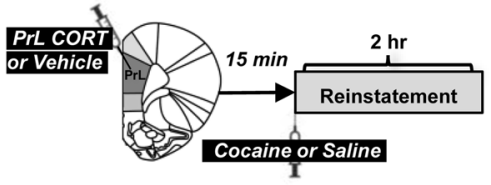

B. Female PrL-PFC CORT-potentiated reinstatement

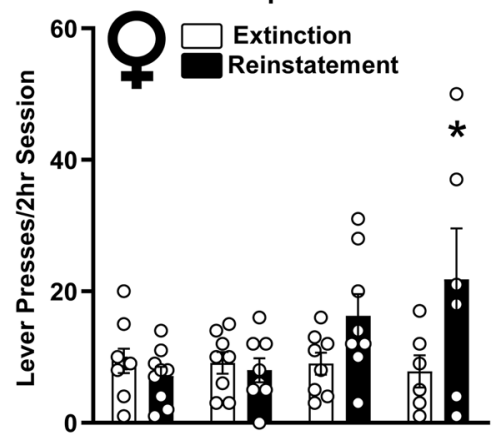

PrL-PFC CORT

$50 \mathrm{ng} / 0.3 \mu \mathrm{L}$

Cocaine

$1.25 \mathrm{mg} / \mathrm{kg}$

C. Reinstatement timeline

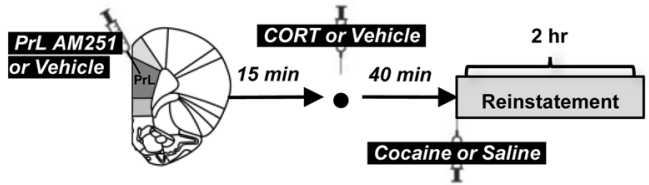

D. Female PrL-PFC CB1R antagonism of CORTpotentiated reinstatement

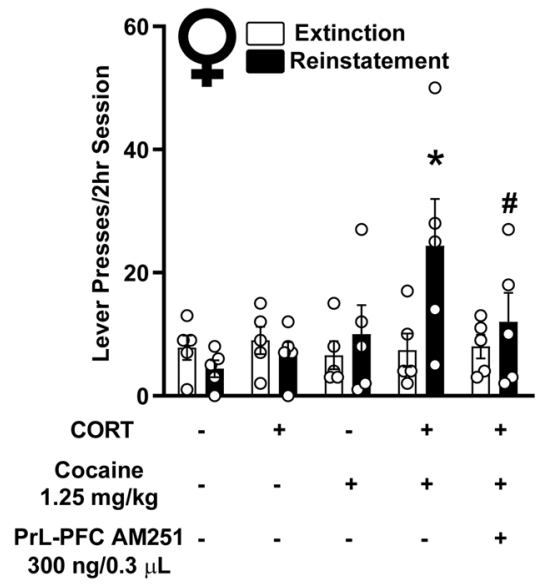

E. Representative Traces
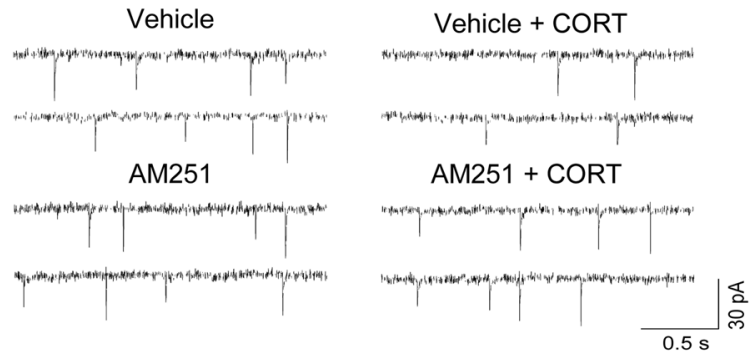

F-G. PrL-PFC CB1R-dependent CORT effects on inter-event interval cumulative probability
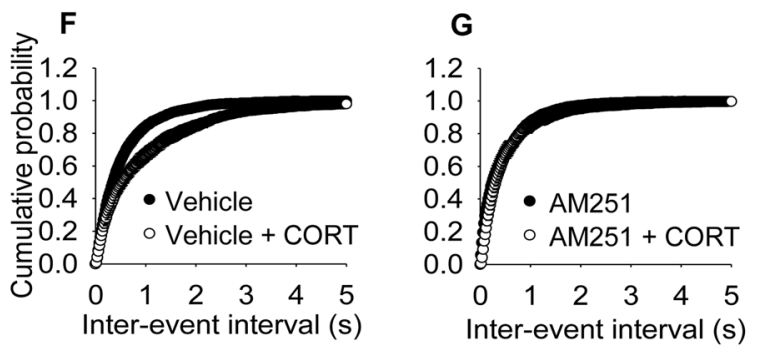

H-I. PrL-PFC CB1R-dependent CORT effects on amplitude cumulative probabilitv
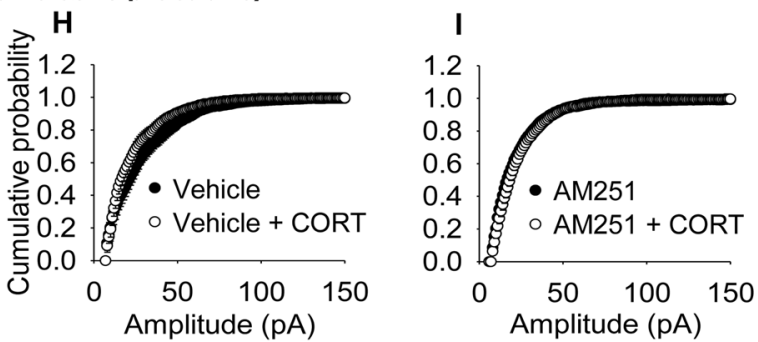

J-K. PrL-PFC CB1R-dependent CORT effects on mIPSC frequency and amplitude
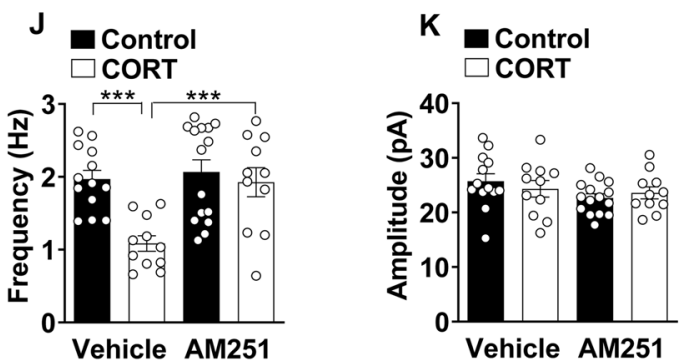

Fig. 5 PrL-PFC CORT is sufficient and CB1R activation is necessary for both potentiated reinstatement and suppression of pyramidal neuron inhibitory activity in females. Within $x$-axis labels, " + " symbols indicate administration of the variable of interest (e.g., cocaine), whereas "-" symbols indicate administration of the associated control condition (e.g., saline). a Reinstatement timeline for PrL-PFC CORTpotentiated reinstatement in females. b Female intra-PrL CORT $(50 \mathrm{ng} / 0.3 \mu \mathrm{L})$ potentiates reinstatement to $1.25 \mathrm{mg} / \mathrm{kg}$ cocaine $\left(n=13\right.$; ${ }^{*} p<$ 0.05 vs. extinction). c Reinstatement timeline for examination of effects of PrL-PFC AM251 on CORT-potentiated reinstatement in females. d Female intra-PrL AM251 $(300 \mathrm{ng} / 0.3 \mu \mathrm{L})$ prevents ip CORT-potentiation of reinstatement to $1.25 \mathrm{mg} / \mathrm{kg}$ cocaine $\left(n=7\right.$; ${ }^{*} p<0.05 \mathrm{vs}$. extinction). CORT-potentiated reinstatement was observed following PrL sham injections $\left({ }^{*} p<0.05\right.$ vs. extinction and each of the other reinstatement conditions) and was significantly attenuated by intra-PrL AM251 ( ${ }^{~} p<0.05$ vs. veh/CORT/cocaine). e Representative traces for recordings from female PrL-PFC layer V/VI pyramidal neurons following CORT and AM251. f PrL-PFC CORT suppression of inter-event interval cumulative probability. g PrL-PFC AM251 inhibition of CORT suppression of inter-event interval cumulative probability. $\mathbf{h}$ PrL-PFC CORT effects on amplitude cumulative probability. i PrL-PFC AM251 inhibition of CORT effects on amplitude cumulative probability. $\mathbf{j}$ PrL-PFC AM251 inhibition of CORT suppression of mIPSC frequency ${ }^{* * *} p<0.05$ vs. Cort or Vehicle). $k$ PrL-PFC AM251 inhibition of CORT effects on mIPSC amplitude. Data are represented as mean \pm SEM. 
ANOVA revealed a main effect of reinstatement $\left(F_{(1,20)}=4.671, p\right.$ $<0.05)$ and a significant interaction $\left(F_{(4,20)}=4.333, p<0.05\right)$. Posthoc testing revealed that, while reinstatement was not observed following CORT/saline or vehicle $/ 1.25 \mathrm{mg} / \mathrm{kg}$ cocaine, the combination of CORT and cocaine produced reinstatement following intra-PrL vehicle $(p<0.01$ vs. PrL sham/vehicle/saline; sham/ CORT/saline; sham $/$ vehicle $/ 1.25 \mathrm{mg} / \mathrm{kg}$ cocaine and extinction). Moreover, potentiated cocaine seeking was blocked by intra-PrL AM251 ( $p<0.05$ vs. intra-PrL sham/CORT/cocaine). Histology and cannula placements are depicted in Fig. S5b, d.

CB1R-dependent effects of CORT on inhibitory synaptic transmission in the PrL-PFC. As in males [13], CORT produced a CB1Rdependent reduction in inhibitory currents in PrL-PFC pyramidal neurons in females. Whole-cell recordings were taken from layer $V$ pyramidal neurons, and miniature IPSCs (mIPSCs) were assessed upon bath perfusion of vehicle, CORT $(1 \mu \mathrm{M})$, AM251 $(2 \mu \mathrm{M})$, or CORT + AM251 for 20-60 min (see Fig. 5e for representative traces). CORT $\left(F_{(1,49)}=10.685, p=0.002\right)$ and $\operatorname{AM} 251 \quad\left(F_{(1,49)}=\right.$ 8.965, $p=0.004$ ) had a significant effect on mean mIPSC frequency, and there was a significant CORT $\times$ AM251 interaction $\left(F_{(1,49)}=5.653, p=0.022\right)$. The Tukey's post-hoc and K-S tests indicated CORT increased inter-event intervals of mIPSCs $(p<0.01$; Fig. 5f) and decreased mean mIPSC frequency $(p<0.001, n=$ 11-13; Fig. 5J); both effects were blocked by AM251 (Fig. 5g, j; $p<$ $0.001, n=11-15)$. CORT and AM251 had no significant effects on the cumulative probability plot for mIPSC amplitude distribution ( $p>0.05$; Fig. $5 \mathrm{~h}, \mathrm{i}$ ) or mean mIPSC amplitude (Fig. 5k), indicating that CB1R-mediated CORT effects are specific to mIPSC frequency.

\section{DISCUSSION}

Heightened susceptibility to cocaine-primed reinstatement in females

Our data indicate that females are more sensitive than males to cocaine-primed reinstatement. Despite no differences in acquisition, maintenance, or extinction of cocaine seeking, females display a leftward shift in the dose-response curve for cocaineprimed reinstatement. The observed lack of sex differences in selfadministration using this cocaine dose $(0.2 \mathrm{mg} / 0.2 \mathrm{~mL}$ infusion) and in responding during extinction aligns with previous reports $[34,35]$ and eliminates potential confounds when comparing subsequent reinstatement responding. These findings align with prior reports of enhanced relapse vulnerability in females compared with males [36, 37].

Sex comparison of stress-potentiated reinstatement

To determine if there are sex differences in stress-potentiated cocaine seeking, we compared the effects of footshock on cocaine seeking between males and females. Surprisingly, in contrast to males, footshock failed to potentiate cocaine seeking in females across a wide range of shock intensities. To determine whether this sex difference either reflects a general lack of capacity for stressors to potentiate cocaine seeking in females, or if footshock specifically produces divergent effects, we tested both males and females for the ability of another inescapable stressor, immobilization restraint, to potentiate cocaine seeking. Restraint-potentiated cocaine seeking was observed in both sexes, and the magnitude of reinstatement was similar. Thus, some stressors can promote relapse in both males and females. However, a key difference is that, in females, stressor effects are superimposed on a higher underlying sensitivity to reinstatement, thereby resulting in an increased cumulative risk for drug seeking. Whether sex differences in vulnerability, or resiliency, are observed with other stressors warrants further investigation. However, these observations are generally consistent with clinical reports that cocaine cue-induced craving is increased in the context of stress in women $[38,39]$.
Sex-divergent responses to footshock

The lack of footshock-potentiated cocaine seeking in females was unexpected and could be attributed to several factors. First, females may be differentially sensitive to the effects of footshock on cocaine seeking (e.g., nociception). To explore this possibility, we tested females for reinstatement across a wide range of shock intensities $(0.15-0.90 \mathrm{~mA})$ but did not observe increased drug seeking at any amperage. In addition, all males and females exhibited flinching responses to footshock, indicating both sexes perceived shocks (data not shown). Moreover, as with restraint, the magnitude of the plasma CORT response relative to baseline was comparable between the sexes, although overall CORT levels were higher in females as previously reported $[40,41]$. In addition, there were no differences in physical reactivity or defensive behaviors, including latency to freeze, percent freezing throughout the footshock session, and defensive darting, though there was a trend for more darting in females as previously reported [33]. Sex differences were observed in "affective state" during footshock as indicated by USV measurements. Males displayed a dramatic increase in the number of $22 \mathrm{kHz}$ calls and a decrease in $55 \mathrm{kHz}$ calls. Females displayed only a modest increase in $22 \mathrm{kHz}$ calls, comparable to that seen during restraint in either sex, with no change in the number of $55 \mathrm{kHz}$ calls. This suggests that, despite no observable differences in hormonal or defensive responses, there are stressor-specific sex differences in emotional processing that could influence motivational state and therefore drug seeking. Consistent with this interpretation, comparison of prior studies on social interaction [42], maternal separation [43], and predator odor [44] indicates different stimuli can produce sexdependent differences in USV "signatures" with respect to both total call number and sonographic characteristics. Though studies assessing appetitive stimuli are lacking, no sex differences in $55 \mathrm{kHz}$ USVs are observed when rats exhibit either an amphetamine- or morphine-associated conditioned place preference [45]. Whether stressor-induced USVs vary with estrous phase, or are affected by CORT or CB1R manipulations, will require further investigation.

In contrast to footshock, which only potentiated cocaine seeking in males, restraint-potentiated cocaine seeking in both sexes. This finding was surprising considering that footshock and restraint produced comparable increases in CORT levels, and that CORT-potentiated cocaine seeking, which was observed in both males and females, involves the same PrL-PFC mechanism (i.e., CB1R activation). We conclude that shock differentially recruits other signaling mechanisms and/or pathways in females that compete with or dampen those promoting drug seeking. Clues to which processes are sex-specifically recruited may be provided by differences in the features of restraint vs. footshock and the conditions under which they were tested (e.g., physical/nociceptive nature, ability to express active coping strategies, delivery within or outside of the operant conditioning chamber). Notably, differences between the two stressors can be observed at the level of PFC Fos expression. Females have been reported to show greater restraint-induced increases in PFC c-fos [46] and reduced footshock-induced PFC c-fos increases [47] compared with males.

CORT-potentiated reinstatement: sex comparison, contribution of estrous cycle, sex-dependent pharmacokinetics

We previously reported in males that elevated CORT is necessary for shock-potentiated reinstatement, and that CORT, at a dose that recapitulates stress levels, potentiates cocaine seeking [12]. Here, we report a similar effect in females. Potentiated reinstatement is observed following administration of the same CORT dose $(2 \mathrm{mg} / \mathrm{kg})$ at the same pretreatment time $(40 \mathrm{~min})$, albeit in combination with a lower subthreshold cocaine priming dose $(1.25 \mathrm{mg} / \mathrm{kg}$, vs. $2.5 \mathrm{mg} / \mathrm{kg}$ in males). Although robust CORTpotentiated reinstatement was observed in both sexes, reinstatement tended to be slightly lower in females. 
Since ovarian hormones can influence drug seeking [48], we hypothesized that CORT effects may have covaried with estrous phase. In support of this possibility, CORT-potentiated cocaine seeking was only observed during diestrus and proestrus. This observation is consistent with a previous report that the ability of the pharmacological "stressor", yohimbine, to potentiate reinstatement in response to cocaine-associated cues is most pronounced during diestrus and proestrus [7]. Future studies will determine if the ability of restraint and/or footshock to potentiate cocaine seeking shows similar variation across the estrous cycle.

Unexpectedly, in contrast to our own previous finding that reinstatement in response to $1.25 \mathrm{mg} / \mathrm{kg}$ cocaine alone is heightened during proestrus [26] and results from others who have reported increased cocaine-primed reinstatement during estrus (albeit at a higher priming dose [49-51]) we did not observe significant reinstatement in response to $1.25 \mathrm{mg} / \mathrm{kg}$ cocaine during any estrous phase or significant variation in reinstatement following this cocaine dose across the estrous cycle. Future experiments are needed to clarify how reinstatement in response to higher cocaine priming doses is influenced by the estrous cycle.

In the present study, CORT-potentiated reinstatement was only observed during diestrus, when both progesterone and $17 \beta$ estradiol levels are relatively low and during proestrus when levels of $17 \beta$-estradiol are relatively high. As cocaine-primed reinstatement is generally enhanced during either heightened $17 \beta$ estradiol $[7,26,49,50]$ or lower progesterone phases $[26,50,52,53]$, we speculate that while heightened $17 \beta$ estradiol mediates increased susceptibility to CORT-potentiated reinstatement during proestrus, low progesterone may contribute to heightened potentiated reinstatement during diestrus. This is consistent with the observation that endogenous progesterone levels negatively correlate with reactivity to yohimbine and cocaine cues in cocaine-dependent women [38].

To confirm that CORT administration recapitulated stressorinduced levels in both sexes, plasma levels following CORT injections were compared. Peak total CORT levels following administration were similar in males and females. Consistent with prior reports [40,54], peak levels following either stressor were higher in females, an effect attributable to higher basal levels $[41,54]$. Unexpectedly, CORT clearance was faster in females. In males, total CORT remained elevated $30 \mathrm{~min}$ after injection, while in females total CORT levels not only returned to baseline by $30 \mathrm{~min}$ but were reduced relative to vehicle controls (likely due to feedback inhibition of the HPA axis by administered CORT), a finding that aligns with earlier reports $[55,56]$. Interestingly, despite sex differences in pharmacokinetics, the ability of CORT to potentiate cocaine seeking did not vary between sexes. This is surprising, as plasma CORT, at the time of testing $40 \mathrm{~min}$ post injection, was no longer elevated in females. One explanation is that blood CORT levels do not parallel brain levels, which peak $\sim 20$ min later [57] and may differ in a sex-dependent manner across brain regions [58]. In addition, once CORT is elevated, it may produce persistent signaling that continues to promote cocaine seeking even after CORT elevations dissipate. Notably, while the present findings demonstrate that "stress-level" CORT potentiates cocaine seeking in both males and females, sex differences in CORT sensitivity were not assessed.

\section{A common PrL-PFC mechanism for CORT-potentiated cocaine} seeking in males and females

We previously found that reinstatement-potentiating effects of CORT can be localized to the PrL-PFC in males [13]. Here we report that CORT also acts within the female PrL-PFC to potentiate reinstatement. Consistent with observations in males, effects of CORT within the PrL-PFC are CB1R-dependent in females [13], as intra-PrL delivery of $A M 251$ blocks potentiation of reinstatement following systemic CORT administration. Although we cannot rule out a potential contribution of non-specific behavioral suppression by intra-PrL AM251 to the observed effects on potentiated drug seeking, we previously showed that a systemic AM251 dose that prevents CORT-potentiated cocaine seeking has no effects on primed reinstatement in response to a higher cocaine dose $[59,60]$. As in males $[13,19]$, CORT produces a CB1Rdependent suppression of inhibitory synaptic regulation of layer $\mathrm{V}$ PrL-PFC pyramidal neurons in females. These observations support a mechanistic model in which stressor-induced increases in CORT promote CB1R-dependent suppression of GABAergic constraint of PrL-PFC pyramidal neurons, thereby removing inhibition of output pathways that mediate drug seeking. Further, in contrast to the sexually dimorphic estrogenic endocannabinoid signaling regulation observed in hippocampus [61], our findings suggest that CORT regulation of endocannabinoid signaling in the PrL-PFC involves a similar mechanism in males and females. While not assessed here in females, we previously found that CORT produces an AM251-dependent increase in paired-pulse ratio in PrL-PFC layer V pyramidal neurons in males, supporting a mechanism that involves a CB1R-mediated inhibition of GABA release [13].

\section{CONCLUSION}

Our findings suggest that, by adding to an already heightened sensitivity to cocaine seeking, stress via CORT signaling can further promote cocaine seeking and thus create greater cumulative risk for relapse in females. Understanding the underlying mechanisms may reveal sex-specific relapse interventions and guide treatment.

\section{FUNDING AND DISCLOSURE}

This research was funded by NIH grant DA032895 to JRM and NIH grant DA038663 to JRM and CJH. JRM is a co-founder of, past consultant for, and shareholder in Promentis Pharmaceuticals, Inc. The authors declare no competing financial interests.

\section{ACKNOWLEDGEMENTS}

We would like to thank Drs Hershel Raff and Paul Gasser for validation of and advice concerning CORT assays, Adam Kirry for instruction on footshock reactivity analyses, and Dr Robert Twining for advice concerning USVs.

\section{ADDITIONAL INFORMATION}

Supplementary Information accompanies this paper at (https://doi.org/10.1038/ s41386-020-0674-3).

Publisher's note Springer Nature remains neutral with regard to jurisdictional claims in published maps and institutional affiliations.

\section{REFERENCES}

1. Westermeyer J, Boedicker AE. Course, severity, and treatment of substance abuse among women versus men. Am J Drug Alcohol Abus. 2000;26:523-35.

2. Greenfield SF, Pettinati HM, O'Malley S, Randall PK, Randall CL. Gender differences in alcohol treatment: an analysis of outcome from the COMBINE study. Alcohol Clin Exp Res. 2010;34:1803-12.

3. Gallop RJ, Crits-Christoph P, Ten Have TR, Barber JP, Frank A, Griffin ML et al. Differential transitions between cocaine use and abstinence for men and women. J Consulting Clin Psychol. 2007;75:95-103.

4. Ong KC, Cheong GN, Prabhakaran L, Earnest A. Predictors of success in smoking cessation among hospitalized patients. Respirology. 2005;10:63-9.

5. Carpenter MJ, Upadhyaya HP, LaRowe SD, Saladin ME, Brady KT. Menstrual cycle phase effects on nicotine withdrawal and cigarette craving: a review. Nicotine Tob Res. 2006;8:627-38.

6. Back SE, Brady KT, Jackson JL, Salstrom S, Zinzow H. Gender differences in stress reactivity among cocaine-dependent individuals. Psychopharmacology. 2005; 180:169-76. 
7. Feltenstein MW, Henderson AR, See RE. Enhancement of cue-induced reinstatement of cocaine-seeking in rats by yohimbine: sex differences and the role of the estrous cycle. Psychopharmacology. 2011;216:53-62.

8. Fox HC, Morgan PT, Sinha R. Sex differences in guanfacine effects on drug craving and stress arousal in cocaine-dependent individuals. Neuropsychopharmacology. 2014;39:1527-37.

9. Furnari M, Epstein DH, Phillips KA, Jobes ML, Kowalczyk WJ, Vahabzadeh M, et al. Some of the people, some of the time: field evidence for associations and dissociations between stress and drug use. Psychopharmacology. 2015;232: 3529-37.

10. Preston $\mathrm{KL}$, Kowalczyk WJ, Phillips KA, Jobes $\mathrm{ML}$, Vahabzadeh $\mathrm{M}$, Lin JLL, et al. Exacerbated craving in the presence of stress and drug cues in drug-dependent patients. Neuropsychopharmacology. 2018;43:859-67.

11. Mantsch JR, Baker DA, Funk D, Lê AD, Shaham Y. Stress-induced reinstatement of drug seeking: 20 years of progress. Neuropsychopharmacology. 2016;41:335-56.

12. Graf EN, Wheeler RA, Baker DA, Ebben AL, Hill JE, McReynolds JR, et al. Corticosterone acts in the nucleus accumbens to enhance dopamine signaling and potentiate reinstatement of cocaine seeking. J Neurosci. 2013;33:11800-10.

13. McReynolds JR, Doncheck EM, Li Y, Vranjkovic O, Graf EN, Ogasawara D, et al. Stress promotes drug seeking through glucocorticoid-dependent endocannabinoid mobilization in the prelimbic cortex. Biol Psychiatry. 2018;84:85-94.

14. Kalivas PW, Volkow ND. The neural basis of addiction: a pathology of motivation and choice. Am J Psychiatry. 2005;162:1403-13.

15. Park WK, Bari AA, Jey AR, Anderson SM, Spealman RD, Rowlett JK et al. Cocaine administered into the medial prefrontal cortex reinstates cocaine-seeking behavior by increasing AMPA receptor-mediated glutamate transmission in the nucleus accumbens. J Neurosci. 2002;22:2916-25.

16. Capriles N, Rodaros D, Sorge RE, Stewart J. A role for the prefrontal cortex in stress- and cocaine-induced reinstatement of cocaine seeking in rats. Psychopharmacology. 2003;168:66-74.

17. McFarland K, Lapish CC, Kalivas PW. Prefrontal glutamate release into the core of the nucleus accumbens mediates cocaine-induced reinstatement of drugseeking behavior. J Neurosci. 2003;23:3531-7.

18. Stefanik MT, Moussawi K, Kupchik YM, Smith KC, Miller RL, Huff ML et al. Optogenetic inhibition of cocaine seeking in rats. Addiction Biol 2013;18:50-53.

19. Hill MN, McLaughlin RJ, Pan B, Fitzgerald ML, Roberts CJ, Lee $\Pi$, et al. Recruitment of prefrontal cortical endocannabinoid signaling by glucocorticoids contributes to termination of the stress response. J Neurosci. 2011;31:10506-15.

20. Li CSRS, Kosten TR, Sinha R. Sex differences in brain activation during stress imagery in abstinent cocaine users: a functional magnetic resonance imaging study. Biol Psychiatry. 2005;57:487-94.

21. Zhou L, Pruitt $C$, Shin CB, Garcia AD, Zavala AR, See RE. Fos expression induced by cocaine-conditioned cues in male and female rats. Brain Struct Funct. 2014;219:1831-40.

22. Bland ST, Schmid MJ, Der-Avakian A, Watkins LR, Spencer RL, Maier SF. Expression of $c$-fos and BDNF mRNA in subregions of the prefrontal cortex of male and female rats after acute uncontrollable stress. Brain Res. 2005;1051:90-99.

23. Henricks AM, Berger AL, Lugo JM, Baxter-Potter LN, Bieniasz KV, Petrie G, et al. Sexand hormone-dependent alterations in alcohol withdrawal-induced anxiety and corticolimbic endocannabinoid signaling. Neuropharmacology. 2017;124: 121-33.

24. Chiu CQ, Puente N, Grandes P, Castillo PE. Dopaminergic modulation of endocannabinoid-mediated plasticity at GABAergic synapses in the prefrontal cortex. J Neurosci. 2010;30:7236-48.

25. Rodriguez de Fonseca F, Cebeira M, Martin M, Fernandez-Ruiz JJ. Cannabinoid receptors in rat brain areas: sexual differences, fluctuations during estrous cycle and changes after gonadectomy and sex steroid replacement. Life Sci. 1994;54: 159-70.

26. Doncheck EM, Urbanik LA, DeBaker MC, Barron LM, Liddiard GT, Tuscher JJ, et al. $17 \beta$-estradiol potentiates the reinstatement of cocaine seeking in female rats: role of the prelimbic prefrontal cortex and cannabinoid type- 1 receptors. Neuropsychopharmacology. 2018;43:781-90.

27. Tinnikov AA. Responses of serum corticosterone and corticosteroid-binding globulin to acute and prolonged stress in the rat. Endocrine. 1999;11:145-50.

28. Kirry AJ, Durigan DJ, Twining RC, Gilmartin MR. Estrous cycle stage gates sex differences in prefrontal muscarinic control of fear memory formation. Neurobiol Learn Mem. 2019;161:26-36.

29. Colom-Lapetina J, Li AJ, Pelegrina-Perez TC, Shansky RM. Behavioral diversity across classic rodent models is sex-dependent. Front Behav Neurosci. 2019;13:45.

30. Barker DJ, Simmons SJ, West MO. Ultrasonic vocalizations as a measure of affect in preclinical models of drug abuse: a review of current findings. Curr Neuropharmacol. 2015;13:193-210.

31. Mittal N, Thakore N, Bell RL, Maddox WT, Schallert T, Duvauchelle CL. Sex-specific ultrasonic vocalization patterns and alcohol consumption in high alcoholdrinking (HAD-1) rats. Physiol Behav. 2019;203:81-90.
32. Van der Kloot W. The regulation of quantal size. Prog Neurobiol. 1991;36:93-130.

33. Gruene TM, Flick K, Stefano A, Shea SD, Shansky RM. Sexually divergent expression of active and passive conditioned fear responses in rats. eLife. 2015;4: e11352.

34. Roth ME, Carroll ME. Sex differences in the escalation of intravenous cocaine intake following long- or short-access to cocaine self-administration. Pharmacol Biochem Behav. 2004;78:199-207.

35. Jackson LR, Robinson TE, Becker JB. Sex differences and hormonal influences on acquisition of cocaine self-administration in rats. Neuropsychopharmacology. 2006;31:129-38.

36. Carroll ME, Lynch WJ. How to study sex differences in addiction using animal models. Addiction Biol. 2016;21:1007-29.

37. Becker JB, Koob GF. Sex differences in animal models: focus on addiction. Pharmacol Rev. 2016;68:242-63.

38. Moran-Santa Maria MM, McRae-Clark A, Baker NL, Ramakrishnan V, Brady KT. Yohimbine administration and cue-reactivity in cocaine-dependent individuals. Psychopharmacology. 2014;231:4157-65.

39. Moran LM, Kowalczyk WJ, Phillips KA, Vahabzadeh M, Lin JLL, Mezghanni M, et al. Sex differences in daily life stress and craving in opioid-dependent patients. Am J Drug Alcohol Abus. 2018;44:512-23.

40. Lu J, Wu XYY, Zhu QBB, Li J, Shi LGG, Wu JLL, et al. Sex differences in the stress response in SD rats. Behavioural Brain Res. 2015;284:231-7.

41. Bertholomey ML, Nagarajan V, Torregrossa MM. Sex differences in reinstatement of alcohol seeking in response to cues and yohimbine in rats with and without a history of adolescent corticosterone exposure. Psychopharmacology. 2016;233:2277-87.

42. Bowers JM, Perez-Pouchoulen M, Edwards NOS, McCarthy MM. Foxp2 mediates sex differences in ultrasonic vocalization by rat pups and directs order of maternal retrieval. J Neurosci. 2013;33:3275-83.

43. Zala SM, Reitschmidt D, Noll A, Balazs P, Penn DJ. Sex-dependent modulation of ultrasonic vocalizations in house mice (Mus musculus musculus). PLoS ONE. 2017;12:e0188647.

44. Blanchard RJ, Agullana R, McGee L, Weiss S, Blanchard DC. Sex differences in the incidence and sonographic characteristics of antipredator ultrasonic cries in the laboratory rat (Rattus norvegicus). J Comp Psychol. 1992;106:270-7.

45. Knutson B, Burgdorf J, Panksepp J. High-frequency ultrasonic vocalizations index conditioned pharmacological reward in rats. Physiol Behav. 1999;66:639-43.

46. Bello NT, Walters AL, Verpeut JL, Caverly J. Dietary-induced binge eating increases prefrontal cortex neural activation to restraint stress and increases binge food consumption following chronic guanfacine. Pharmacol Biochem Behav. 2014:125:21-8

47. Trentani A, Kuipers SD, te Meerman GJ, Beekman J, ter Horst GJ, den Boer JA Immunohistochemical changes induced by repeated footshock stress: revelations of gender-based differences. Neurobiology Dis. 2003;14:602-18.

48. Anker JJ, Carroll ME. Females are more vulnerable to drug abuse than males: evidence from preclinical studies and the role of ovarian hormones. Current Topics Behavioral. Curr Top Behav Neurosci. 2011;8:73-96.

49. Kippin TE, Fuchs RA, Mehta RH, Case JM, Parker MP, Bimonte-Nelson HA et al. Potentiation of cocaine-primed reinstatement of drug seeking in female rats during estrus. Psychopharmacology. 2005;182:245-52.

50. Feltenstein MW, See RE. Plasma progesterone levels and cocaine-seeking in freely cycling female rats across the estrous cycle. Drug Alcohol Depend. 2007;89:183-9.

51. Larson EB, Carroll ME. Estrogen receptor beta, but not alpha, mediates estrogen's effect on cocaine-induced reinstatement of extinguished cocaine-seeking behavior in ovariectomized female rats. Neuropsychopharmacology. 2007;32: 1334-45.

52. Sofuoglu M, Babb DA, Hatsukami DK. Effects of progesterone treatment on smoked cocaine response in women. Pharmacol Biochem Behav. 2002;72: 431-5.

53. Sinha R, Fox H, Hong KIl, Sofuoglu M, Morgan PT, Bergquist KT. Sex steroid hormones, stress response, and drug craving in cocaine-dependent women: implications for relapse susceptibility. Exp Clin Psychopharmacol. 2007;15:445-52.

54. Critchlow V, Liebelt RA, Bar-Sela M, Mountcastle W, Lipscomb HS. Sex difference in resting pituitary-adrenal function in the rat. Am J Physiol. 1963;205: 807-15.

55. Windle RJ, Wood SA, Lightman SL, Ingram CD. The pulsatile characteristics of hypothalamo-pituitary-adrenal activity in female Lewis and Fischer 344 rats and its relationship to differential stress responses. Endocrinology. 1998;139: 4044-52.

56. Choleris E, Cazzin L, Lymer JM, Amor TR, Lu R, Kavaliers M et al. Acute corticosterone sexually dimorphically facilitates social learning and inhibits feeding in mice. Neuropharmacology. 2013;75:191-200.

57. Droste SK, de Groote L, Atkinson HC, Lightman SL, Reul JMHM, Linthorst AC. Corticosterone levels in the brain show a distinct ultradian rhythm but a delayed response to forced swim stress. Endocrinology. 2008;149:3244-53. 
Sex, stress, and prefrontal cortex: influence of biological sex on...

EM Doncheck et al.

58. Sze Y, Gill AC, Brunton PJ. Sex-dependent changes in neuroactive steroid concentrations in the rat brain following acute swim stress. J Neuroendocrinol. 2018;30:e12644.

59. McReynolds JR, Doncheck EM, Vranjkovic O, Ganzman GS, Baker DA, Hillard CJ et al. CB1 receptor antagonism blocks stress-potentiated reinstatement of cocaine seeking in rats. Psychopharmacology 2016;233:99-109.
60. Xi ZX, Gilbert JG, Peng XQ, Pak AC, Li X, Gardner EL. Cannabinoid CB1 receptor antagonist AM251 inhibits cocaine-primed relapse in rats: role of glutamate in the nucleus accumbens. J Neurosci. 2006;26:8531-6.

61. Tabatadze N, Huang G, May RM, Jain A, Woolley CS. Sex differences in molecular signaling at inhibitory synapses in the hippocampus. J Neurosci. 2015;35: $11252-65$. 